\title{
"They Just Want Us to Exist as a Trash Can": Parents of Children with Autism Spectrum Disorder and Their Perspectives to School-Based Bullying Victimization
}

\author{
Hui Zhang ${ }^{1}\left[\mathbb{D}^{-}\right.$Chun Chen $^{2}$
}

Accepted: 3 July 2021 / Published online: 21 July 2021

(c) The Author(s) 2021

\begin{abstract}
Little is known about parents' perspectives on school-based bullying victimization of children with autism spectrum disorder (ASD) in China. This study began by interviewing 16 parents about their experiences with their children ( 7 to 15 years old) at school in China under the inclusive education policy. Most of the parents' responses indicated the existence and the severity of school-based bullying victimization of their children with ASD. Our findings indicated that bullying victimization at school was a concern for children with ASD and their parents were frequently victimized. Parents reported that they dealt with bullying victims at school independently and tended to hold a pessimistic view about their bullying victimization. The study highlights the importance of incorporating parents' voices in understanding bullying victimization of students with ASD and proposing potential implications in bullying prevention and advocacy with this group of students in mainstream schools in China.
\end{abstract}

Keywords Parent perception - Inclusive education · Autism spectrum disorder · Interpretive phenomenological analysis · School-based bullying victimization

Bullying has become one of the most concerning problems in schools across the world. Previous research has shown a wide range of adverse outcomes of bullying victimization on youths' academic performance and social-emotional wellbeing (e.g., Reijntjes et al., 2010). According to studies, children and adolescents with various illnesses and conditions may be more likely to be bullied, including those with autism spectrum disorder (ASD), attention deficit disorders, learning difficulties, and behavioral or emotional disorders (Adams et al., 2013; Storch et al., 2006; Twyman et al., 2010). Meanwhile, several groups of youth, such as youth with developmental disorders (Rose et al., 2009), particularly children with ASD (Maiano et al., 2016), have been traditionally stigmatized as targets of bullying in school culture

Hui Zhang

hui_zhang@ucsb.edu

1 Department of Education, University of California, Santa Barbara, Santa Barbara, CA, USA

2 Department of Counseling, Clinical, and School Psychology, University of California, Santa Barbara, Santa Barbara, CA, USA across the literature (National Academies of Sciences, Engineering, and Medicine, 2016). However, bullying research has focused predominantly on students in the general education settings, while little attention has been given to students with special needs at school. Furthermore, the investigation of the bullying experiences of students with ASD in China is far less understood than in other regions.

Understanding Chinese parents' perception of bullying victimization through a bottom-up approach is crucial for developing culturally responsive bullying prevention and intervention strategies that address Chinese parents' concerns and better accommodate students' needs at school. Despite laws and regulations providing public education to students with disabilities, there is no clear guidance to advise public schools on including and supporting students with ASD in regular school settings. The Nine-Year Compulsory Education Law stipulates that students with disabilities shall receive free public education until ninth grade (National People's Congress, 2018b), and the Law on the Protection of Persons with Disabilities since 1990 further obliges that public schools shall provide equal education opportunities to students with disabilities as their peers without disabilities (National People's Congress, 2018a). Both laws lack detailed 
guidance on the implementation and procedural safeguards to guarantee service and accommodation as stipulated in legal documents. Researchers indicated that public schools often refuse students with ASD in China due to a lack of understanding of ASD (Cui, 2016; Mccabe, 2003; Su et al., 2020). Students with ASD and their families are facing various challenges associated with inclusive education, such as the lack of special education teachers, the lack of support from schools, and discrimination against students with ASD and their families from society (Huang et al., 2013; Ochoa et al., 2017; Xu \& Zhu, 2016).

Moreover, empirical studies examining parents' perceptions of bullying are limited (Chen et al., 2020). The purpose of this study was to gain a better understanding of Chinese parents' perspectives of their children with ASD regarding school-based bullying victimization.

School-based bullying victimization is defined as the repeated in-person experience of being subjected to intentionally aggressive behaviors perpetrated by others. Power imbalance occurs between bully/ies and victim/s (Olweus, 1993) in the school context. It has been found that children struggling with social skills and with fewer friends were more likely to be marginalized and unprotected in social groups and, thus, more vulnerable to power abuse by their peers (Delfabbro et al., 2006; Sterzing et al., 2012). Studies found the rate of bullying victimization at school to be more prevalent among children with behavioral, emotional, or developmental disorders such as ASD than their typically developing counterparts (Van Cleave and Davis, 2006) . The prevalence rates of bullying victimization in adolescents with ASD in general education and special education settings collected from multi-informant reports (i.e., self, peer, teacher reports) were documented from 7 to up to $75 \%$ (Van Roekel et al., 2010; Due et al., 2005; Little, 2001) . For example, one study found that children in the USA with ASD were four times more likely to experience bullying than typically developing classmates (55\% vs. 13\%; Little, 2001). Another study reported by 34 parents of students with ASD indicated the prevalence of bullying victimization to be $65 \%$ (Carter, 2009). A meta-analysis study has also suggested that school-aged children and adolescents with ASD were at a higher risk of school bullying victimization than were those without ASD (Maiano et al., 2016). When the general bullying literature was broken down into distinct types of victimization, it was discovered that verbal and relational forms of victimization were more prevalent than physical forms of bullying among students with ASD (Cappadocia et al., 2012).

In the context of public educational settings in China, students with ASD often attend full-day classes in general education settings with schoolteachers and school psychology support. General education teachers usually lack the awareness of how to provide accommodations and integrate students with ASD into an inclusive classroom setting (Huang et al., 2013). It poses more challenges for Chinese students with ASD in a mainstream classroom setting than typically developing students, particularly when they experience bullying from peers. Therefore, the current study aimed to deepen the understanding of their bullying victimization in school from the parents' perspectives.

With Confucianism being the fundamental philosophy of Chinese culture, China has traditionally placed high values on education (Poon-McBrayer \& McBrayer, 2014). However, when it comes to serving the needs of students with ASD, mainstream schools lack individualized academic and social-emotional support (Liu et al., 2016). Equal educational access to regular school classroom for children with ASD is still limited in China (Zhang \& Spencer, 2015). Despite many parents desire to have their children attend a regular school and be included in the classroom, teachers are not typically trained to provide sufficient instructions to students with ASD in mainstream classrooms (Huang et al., 2013). According to the prior studies, regular classroom teachers are usually unfamiliar with students' needs with ASD and create an inclusive school and classroom environment for them. Traditional public schools in China typically include a large student body in classrooms, which could further result in a lack of quality of services for children with ASD (Liu et al., 2016) and limited attention and support from teachers (Clark et al., 2019).

Moreover, parental advocacy to assert their children's rights in the education system is rare in Chinese societies (Deng et al., 2001). When parents become aware of the difficulties their child might experience at school, they are likely to be reserved from contesting school policies due to Confucianism's emphasis on maintaining harmony and respecting authorities (Poon-McBrayer \& McBrayer, 2014). Families who raise a child with ASD in China often face additional stress from society and experience challenges with obtaining and supporting their child's equal access to education. The collectivistic culture in China imposes the need for families to strictly adhere to community and societal norms (Huang $\&$ Zhou, 2016). Parents are often excluded or ostracized by their communities by not being invited to have their child socialize with peers, which causes them to have more stress due to the lack of community support (Clark et al., 2019). Therefore, it is necessary to understand Chinese parents' perspectives on children having ASD and their experiences with their children's education in a culturally sensitive context.

From a contextual perspective, youth's relationships within their proximal social contexts, such as the family and peer groups, might significantly impact their victimization experiences (Cappadocia et al., 2012). Particularly for younger-aged students and students with special needs, parents represent the primary socialization agent (Cappadocia 
et al., 2012). Particularly among students with ASD who have social difficulties, most of the time spent on social interaction is likely to be with their parents (Kloosterman et al., 2013). It has also been reported that parents were often involved in helping their children with ASD build meaningful and stable friendships (Frankel \& Whitham, 2011). Therefore, parents having children with ASD tend to play an essential role in facilitating their children's social development and social awareness.

Parents' reports have become the standard for reporting bullying experiences among children with ASD (Cappadocia et al., 2012; Zablotsky et al., 2014). Previous studies also showed that children with ASD would be more likely to confide in and disclose their experiences to their parents than other stakeholders (Kloosterman et al., 2013). Parents of children with ASD often play a critical role in their child's social development and tend to be more involved in students' social lives (Cappadocia et al., 2012). As a result, parent reports are critical for understanding how students with ASD are bullied and guiding schools to prevent and intervene in bullying victimization.

This study presented a nuanced examination of parents' perceptions of bullying victimization at school and the difficulties they faced. The qualitative character of the study will provide a better understanding of how Chinese parents are affected by their child's bullying experiences and the challenges they confront in these instances.

\section{Methods}

This study was conducted in 2019 using the interpretive phenomenological analysis (IPA) method (Alase, 2017; Noon, 2018). IPA seeks a close connection between the researcher and participants instead of applying rigid formulated procedures or clinging to predetermined theoretical lenses. It requires researchers to keep themselves from theorizing about participants' experiences before engaging in the dialogue with interviewees. In this study, researchers focused on unfolding meaning by listening to participants' thoughts and feelings (Sohn et al., 2017) from first-person perspectives of what it is like for them as parents of children with ASD when experiencing school bullies.

\section{Participants}

Participants were recruited from two parents' online groups through WeChat, one of the most popular instant message platforms in China. One group had 493 members as of $09 / 18 / 2019$, and the other had 386 members as of 09/18/2019. Parents contacted the first author to indicate if they were interested in joining. Initially, there were seventeen parents indicating interest by contacting the first author.
Due to one parent dropping out, a total sample of sixteen parents participated in this research. Parents from the two groups were anonymous to each other except for their locations, and their children's ages. There are 15 females (biological mothers of children with ASD) and one male (biological father of a child with ASD) in the sample. Although not specifically asked in the questionnaire, all participants are from different households because children's information does not overlap with each other. Table 1 presents more details of participants' characteristics.

Participants were selected according to purposeful sampling criteria (Patton, 2005). Purposeful sampling is a technique widely used in qualitative research to identify and choose information-rich cases for the most effective use of limited resources (Patton, 2005). The sampling procedure involves identifying and selecting individuals or groups of exceptionally knowledgeable or experienced individuals with a phenomenon of interest. In addition to knowledge and experience, researchers noted the importance of availability, willingness to participate, and the ability to communicate experiences and opinions in an articulate, expressive, and reflective manner (Patton, 2005). Two criteria were used when recruiting parent participants: (1) those with knowledge of and active participation in their children's education experience and (2) parents of school-age children (7 to 15 years old) who have been identified with ASD. The participating parents are mainly college-educated and are from middle-income families.

\section{Procedures}

In this study, semi-structured online interviews were conducted through WeChat. Each interview lasted approximately $1 \mathrm{~h}$ and was recorded upon the consent of the interviewees. Before the interviews, a demographic questionnaire was distributed to the participants and returned to the first author before the interviews. The first author also provided the Chinese version of the interview protocol to participants. In the protocol, parents were mainly asked about their experiences of having their children at school in China under the inclusive education policy. Throughout the interviews, most of the parents' responses indicated the existence and the severity of school-based bullying victimization of their children with ASD. Therefore, the current study was generated.

The grand tour questions in semi-structured interviews were designed with the following focus: (a) parents' experiences before school (e.g., could you please tell me something about what made you start to concern for your child's development?), (b) parents' experience advocating for school education (e.g., could you please share the most important events that you think are decisive for your child to be able to go to school?), and (c) parents' expectations for school (e.g., how would you value the importance 
Table 1 Participants' characteristics

\begin{tabular}{|c|c|c|c|c|c|c|c|c|}
\hline Parent number & $\begin{array}{l}\text { Gender } \\
\text { (parent) }\end{array}$ & Age (parent) & $\begin{array}{l}\text { Education } \\
\text { level }\end{array}$ & $\begin{array}{l}\text { Age of child } \\
\text { with autism }\end{array}$ & $\begin{array}{l}\text { Gender of } \\
\text { child with } \\
\text { autism }\end{array}$ & $\begin{array}{l}\text { Type of } \\
\text { school child } \\
\text { signed up }\end{array}$ & $\begin{array}{l}\text { Employment } \\
\text { conditions }\end{array}$ & $\begin{array}{l}\text { Family annual } \\
\text { income (USD) }\end{array}$ \\
\hline 1 & Female & $30-39$ & College & 10 & Male & Public school & Unemployed & $15,000-31,000$ \\
\hline 2 & Female & $30-39$ & College & 8 & Male & Public school & Part-time job & $77,000-93,000$ \\
\hline 3 & Female & $30-39$ & $\begin{array}{c}\text { Bachelor's } \\
\text { degree }\end{array}$ & 8 & Female & Public school & Part-time job & $31,000-46,000$ \\
\hline 4 & Female & $30-39$ & $\begin{array}{c}\text { Bachelor's } \\
\text { degree }\end{array}$ & 7 & Male & Public school & $\begin{array}{l}\text { Full-time } \\
\text { employed }\end{array}$ & $15,000-31,000$ \\
\hline 5 & Female & $30-39$ & College & 10 & Male & Private school & $\begin{array}{l}\text { Full-time } \\
\text { employed }\end{array}$ & $15,000-31,000$ \\
\hline 6 & Female & $30-39$ & $\begin{array}{l}\text { Bachelor's } \\
\text { degree }\end{array}$ & 7 & Male & $\begin{array}{l}\text { Homeschool- } \\
\text { ing }\end{array}$ & $\begin{array}{l}\text { Full-time } \\
\text { employed }\end{array}$ & $8,000-15,000$ \\
\hline 7 & Female & $30-39$ & $\begin{array}{r}\text { Master's } \\
\text { degree }\end{array}$ & 11 & Male & Public school & Part-time job & $77,000-155,000$ \\
\hline 8 & Female & $30-39$ & $\begin{array}{r}\text { Master's } \\
\text { degree }\end{array}$ & 6 & Male & Public school & $\begin{array}{l}\text { Full-time } \\
\text { employed }\end{array}$ & $62,000-77,000$ \\
\hline 9 & Female & $30-39$ & $\begin{array}{c}\text { Doctoral } \\
\text { degree }\end{array}$ & 8 & Male & Public school & $\begin{array}{l}\text { Full-time } \\
\text { employed }\end{array}$ & $62,000-77,000$ \\
\hline 10 & Female & $40-49$ & $\begin{array}{r}\text { Master's } \\
\text { degree }\end{array}$ & 13 & Male & $\begin{array}{l}\text { Homeschool- } \\
\text { ing }\end{array}$ & $\begin{array}{l}\text { Full-time } \\
\text { employed }\end{array}$ & $46,000-62,000$ \\
\hline 11 & Female & $30-39$ & $\begin{array}{l}\text { Bachelor's } \\
\text { degree }\end{array}$ & 8 & Male & Private school & Unemployed & $62,000-77,000$ \\
\hline 12 & Male & $40-49$ & College & 11 & Male & Special school & $\begin{array}{l}\text { Full-time } \\
\text { employed }\end{array}$ & $15,000-31,000$ \\
\hline 13 & Female & $40-49$ & $\begin{array}{r}\text { Master's } \\
\text { degree }\end{array}$ & 14 & Male & Public school & $\begin{array}{l}\text { Full-time } \\
\text { employed }\end{array}$ & $46,000-62,000$ \\
\hline 14 & Female & $30-39$ & College & 10 & Female & Public school & Unemployed & $15,000-31,000$ \\
\hline 15 & Female & $30-39$ & $\begin{array}{r}\text { Master's } \\
\text { degree }\end{array}$ & 7 & Male & Public school & Unemployed & $15,000-31,000$ \\
\hline 16 & Female & $40-49$ & $\begin{array}{c}\text { Doctoral } \\
\text { degree }\end{array}$ & 5 and 13 & $\begin{array}{l}\text { Female and } \\
\text { Male }\end{array}$ & Special school & $\begin{array}{l}\text { Full-time } \\
\text { employed }\end{array}$ & $46,000-62,000$ \\
\hline
\end{tabular}

for your child to stay in a regular classroom?). Follow-up probing questions were asked depending on the answers of each participant.

All interviews were conducted in Mandarin Chinese, and questionnaires were also provided in Mandarin Chinese, the participants' native language. The authors obtained permission from all participants to tape-record the conversations. The first author transcribed the interviews and coded the transcriptions.

\section{Data Analysis}

As one of IPA's essential elements, researchers are encouraged to adopt flexible methods according to their research objective and are encouraged to be innovative in their thinking (Alase, 2017). For this research, there were four steps for data analysis as suggested by Thornberg and Charmaz (2014) . First, the data was analyzed line-by-line. The first author considered the original data and used short and simple language to convey the emerging facts. The second step was memo writing, in which the researchers ran through line-by-line coding to the final stages of forming higherlevel categories. The content of this step represents what the authors thought about each interview and themes arising from each interview. The third step focused on coding or concurrent topic coding; in this step, the first author reexamined the line-by-line codes and classified them based on their content similarities, which means line-by-line codes under the same category illustrated the similar issue. The fourth step was to develop themes involving a grouping of codes that addressed identical challenges in school-based bullying among parents.

\section{Results}

Three primary findings emerged from our analysis as listed in Table 2: (a) parents' interpretation of bullying as an unavoidable part of life, (b) parents are also victims of school bullying when they accompany their children at school, and 


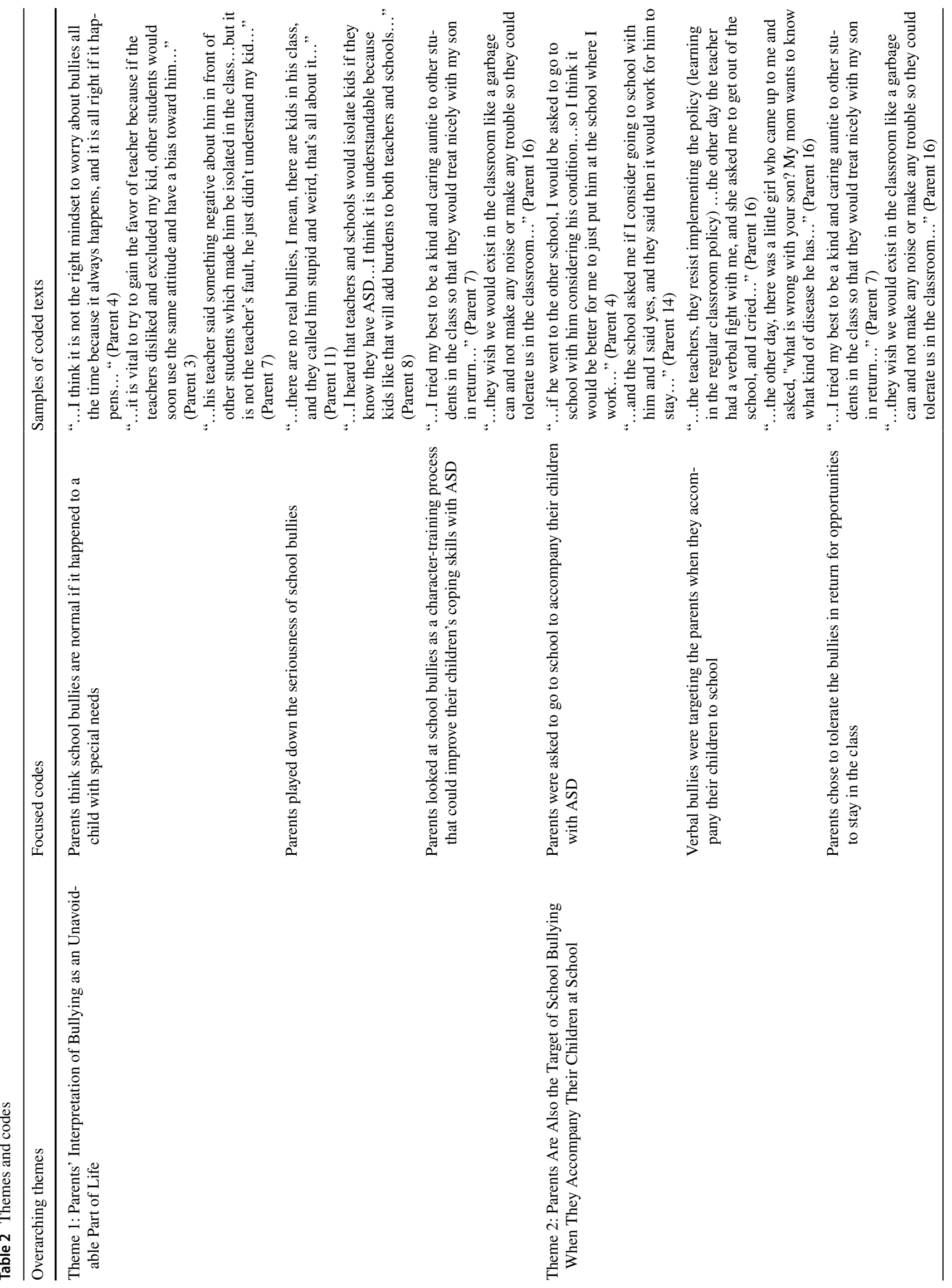




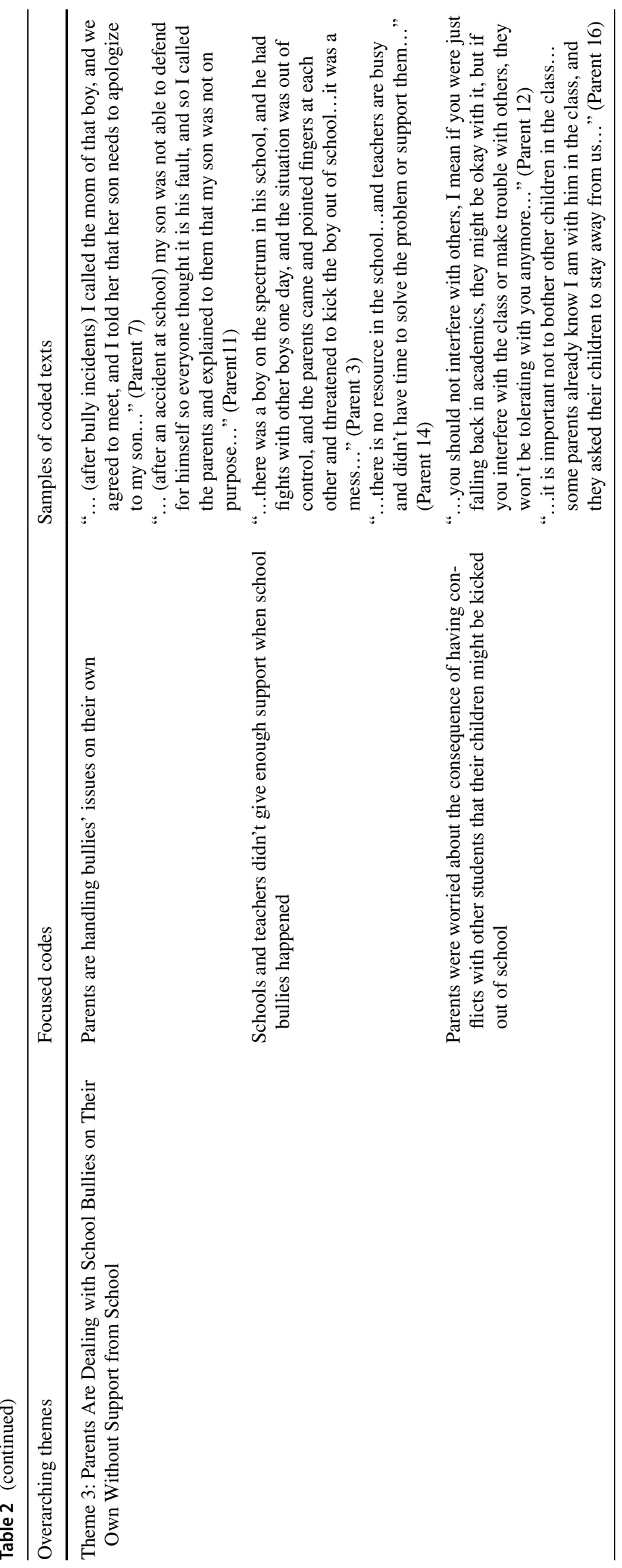


(c) parents are dealing with school bullies on their own without support from the school.

\section{Theme 1: Parents' Interpretation of Bullying as An Unavoidable Part of Life}

When asked about parents' perspectives and experiences regarding school bullying, parents expressed worries about incidents with bullies. However, 5 out of 16 parents interpreted bullying at school as an opportunity to develop an adaptive skill. They viewed bullying as constituting necessary life lessons for their children. This attitude seemed to be internalization and acceptance of stigma directed at their children as if it were to be expected in life. There is a strong and stoic trend in Chinese culture whereby painful experiences are viewed as expected and even necessary, and this is consistent with our findings in this study.

"...I think it is not the right mindset to worry about bullies all the time because it always happens, and it is all right if it happens... bullies from others will improve his ability in handling things like this..." (Parent 4)

Some parents further indicated they think school bullying is normal for children with ASD and pointed out that teachers' attitudes toward their children are essential to whether a child with ASD will be excluded or isolated at school. Because of this, parents tended to agree with teachers' viewpoints to gain the favor of teachers as a return benefit.

"...it is vital to try to gain the favor of the teacher because of the teachers disliked and excluded my kid, other students would soon use the same attitude and have a bias toward him..." (Parent 3)

“...his teacher said something negative about him in front of other students which made him be isolated in the class...but it is not the teacher's fault, he just didn't understand my kid..." (Parent 7)

According to Parent 7, some parents of children with ASD may cope with their child's bullying victimization by rationalizing the attackers. They might perceive others' misunderstanding toward their child's behaviors as inevitable and common. Under this situation, parents are in a submissive position, especially when they must accompany their children at school upon the request of schools, making them also the targets of school bullies in this culture.

\section{Theme 2: Parents Are Also the Target of School Bullying When They Accompany Their Children at School}

Among 16 participants in this study, 7 of them accompanied their children at school full-time. According to participants, going to school with their children was requested by the schools. This situation meant that parents could not seek paid employment, representing a substantial income loss for these families. For example, a mother who worked for a school where her son enrolled explained she would rather keep him at the school because she could keep her work while taking care of him simultaneously.

“...if he went to the other school, I would be asked to go to school with him considering his condition... so I think it would be better for me to just put him at the school where I work..." (Parent 4)

"... and the school asked me if I consider going to school with him and I said yes, and they said then it would work for him to stay..." (Parent 14)

The situation that requires parents to be physically present in the class is a source of embarrassment for parents and makes them the targets of discrimination.

"...the teachers, they resist implementing the policy (learning in the regular classroom policy) ...they wish we would exist in the classroom like a garbage can and not make any noise or make any trouble so they could tolerate us in the classroom..." (Parent 16)

When facing verbal bullies, parents normally chose to tolerate the harassment and tried to gain empathy from others.

“...I tried my best to be a kind and caring auntie to other students in the class so that they would treat nicely with my son in return..." (Parent 7)

According to these parents, teachers in the traditional school negatively affect both children with ASD and their parents. This finding is consistent with prior research that due to a lack of understanding of disabilities, regular classroom teachers generally hold a negative attitude toward inclusive education practices. Typically, they do not believe students with special needs could benefit from regular education settings (Li, 2016). Also, the negative attitude could come from other students in the classroom and their parents due to misunderstandings and discrimination.

“...the other day, there was a little girl who came up to me and asked, 'what is wrong with your son? My mom wants to know what kind of disease he has'..." (Parent 16)

In this statement, the student and her parents did not understand ASD. They possibly identify a social stigma that devalues a person with a disability and marks their identity in a discounted manner of inferior status because of their psychological or physical disabilities. 


\section{Theme 3: Parents Are Dealing with School Bullies on Their Own Without Support from School}

In this study, when asked about their opinions on how they handled issues relating to school bullies as parents, participants reported that they dealt with the problems independently without much support from the school.

“... (after bully incidents) I called the mom of that boy, and we agreed to meet, and I told her that her son needs to apologize to my son..." (Parent 7)

“... (after an accident at school) my son was not able to defend for himself, so everyone thought it was his fault, and so I called the parents and explained to them that my son was not on purpose..." (Parent 11)

When asked in a follow-up question about the teachers' resolving bullying issues, parents reported that schools or school teachers had not played a supporting role in the process.

"...there was a boy on the spectrum in his school, and he had fights with other boys one day, and the situation was out of control, and the parents came and pointed fingers at each other and threatened to kick the boy out of school...it was a mess..." (Parent 3)

"...there is no resource in the school... and teachers are busy and didn't have time to solve the problem or support them..." (Parent 14)

Without support from the school, parents worried about the consequences of bullying issues. They were afraid of being further excluded from the regular school settings, even though they are victims of school bullies in these circumstances. For example, the parents below emphasized the importance of "not interfering with others" in the class, acting cautiously out of fear rather than self-discipline out of high moral standards.

“...you should not interfere with others; I mean, if you were just falling back in academics, they might be okay with it, but if you interfere with the class or make trouble with others, they won't be tolerating with you anymore..." (Parent 12)

"...it is important not to bother other children in the class... some parents already know I am with him in the class, and they asked their children to stay away from us..." (Parent 16)

The data indicated that not only are children with ASD experiencing school bullying verbally and physically, and there is insufficient support from schools and schoolteachers to address the importance of zero-tolerance of school bullies. As a result, parents are the only party responsible for resolving school bullying issues.

\section{Discussion}

The purpose of this study was to provide an overview from parents' perspectives on their experiences of their children facing school-based bullying in regular education settings and the efforts they are taking to handle these challenges.

After interviewing 16 parents of children with ASD in China, recruited from different parents' online groups through WeChat, the findings furthered the understanding of parents' experiences when facing school bullies in several ways.

Firstly, we found that parents face discrimination and stigma against their families due to low societal awareness and acceptance of ASD (McCabe, 2007). In our study, 12 out 16 parents reported the incidents relating to bullies at school targeting their children and themselves as parents from different stakeholders, including students without disabilities and their parents, schoolteachers, and school administrations. Under this situation, some parents accept and rationalize the stigma by viewing it as an opportunity to foster adaptivity or interpret it as a preparation for adult life.

Secondly, in this study, parents reported incidents relating to bullies at schools attacking the children and themselves going to schools with them. Schoolteachers and other students verbally bullied parents because they misunderstood ASD. Additionally, in traditional classroom settings, the student with ASD is viewed as unimportant and a "drag on the group." Parents accept this discrimination as usual and rationalize the harassment toward their children as some character-training process. As indicated by Xu et al. (2018), in Chinese society, individuals with disabilities, often perceived as students with the most needs, are unlikely to succeed in an examination-oriented education system. This over-emphasis on test scores overlooks personal development and leads to educational success becoming a privilege reserve for typically developing youth. If special attention were paid to a small, slower developing minority over the class majority, the students with a disability would consequently be victimized.

Lastly, this study shows that parents are avoiding conflicts with other students because they are fearful of being excluded from the traditional school setting. Contrary to Article 10 of the Nine-Year Compulsory Education Law on free public education to all children, we found that parents of children with ASD in this study were in an inferior position compared to those of typically developing children in the regular classroom. According to parents, schools could kick them out of the school because of other parents' dissatisfaction. In this situation, parents are more concerned about not interfering with others in the classroom than whether their children would benefit from the class. This finding is also consistent with the prior studies that suggested 
implementing inclusive education faces the challenge that students with disabilities are often rejected from the regular education settings (Ochoa et al., 2017; Sun et al., 2013).

\section{Limitations}

There are four significant limitations to this research. First, this research's recruitment method may have excluded parents who have no access to online parents' resources or are not interested in online social networking. Therefore, the findings may not be generalized to students from different family backgrounds with various social and economic statuses. For example, most of the participants are college graduates and from middle-class families. Future studies are suggested to include more parents from a diverse social economic backgrounds. The second limitation is the small sample pool (16 participants) in this study, which means that further parent interviews with a larger number of participants could have resulted in different findings and conclusions due to the small sample size of this study. The third limitation is that data from parents of low-income or lesseducated backgrounds were excluded. More comprehensive research involving parents of children with ASD from a wider socioeconomic background may be needed to be more inclusive. Finally, the protocol used in this study might not be explicitly targeting school bullying. Therefore, further investigations may be required in the future that focus primarily on school bullying among children with ASD and other disabilities in China.

\section{Implications for Future Research}

Although the concerns and worries of parents having a child with ASD regarding school bullying and discrimination were documented widely globally, we find that the research of Chinese parents having a child with ASD remained lacking. The majority of existing school bullying victimization research on parents of children with ASD focused more on parents' concerns on the potential negative results of bullying than the interpretations of worry from different theoretical lenses. Therefore, as one of the significant findings in our study, parents' rationalizing and accepting the stigma and bullying of children with ASD in China are a direction worthy of further investigation from different perspectives and theoretical lenses.

\section{Declarations}

Conflict of Interest The authors declare no competing interests.
Open Access This article is licensed under a Creative Commons Attribution 4.0 International License, which permits use, sharing, adaptation, distribution and reproduction in any medium or format, as long as you give appropriate credit to the original author(s) and the source, provide a link to the Creative Commons licence, and indicate if changes were made. The images or other third party material in this article are included in the article's Creative Commons licence, unless indicated otherwise in a credit line to the material. If material is not included in the article's Creative Commons licence and your intended use is not permitted by statutory regulation or exceeds the permitted use, you will need to obtain permission directly from the copyright holder. To view a copy of this licence, visit http://creativecommons.org/licenses/by/4.0/.

\section{References}

Adams, R. E., Fredstrom, B. K., Duncan, A. W., Holleb, L. J., \& Bishop, S. L. (2013). Using self and parent-reports to test the association between peer victimization and accepting symptoms in verbally fluent adolescents with ASD. Journal of Autism and Developmental Disorders, 44(4), 861-872. https://doi.org/10. 1007/s10803-013-1938-0

Alase, A. (2017). The interpretative phenomenological analysis (ipa): A guide to a good qualitative research approach. International Journal of Education and Literacy Studies, 5(2), 9. https://doi.org/10.7575/aiac.ijels.v.5n.2p.9

Cappadocia, M. C., Weiss, J. A., \& Pepler, D. (2012). Bullying experiences among children and youth with autism spectrum disorders. Journal of Autism and Developmental Disorders, 42(2), 266-277. https://doi.org/10.1007/s10803-011-1241-x

Carter, S. (2009). Bullying of students with Asperger syndrome. Issues in Comprehensive Pediatric Nursing, 32, 145-154. https://doi.org/10.1080/01460860903062782

Chen, C., Yang, C., Chan, M., \& Jimerson, S. R. (2020). Association between school climate and bullying victimization: Advancing integrated perspectives from parents and cross-country comparisons. School Psychology, 35(5), 311-320. https://doi.org/ $10.1037 / \mathrm{spq} 0000405$

Clark, E., Zhou, Z., \& Du, L. (2019). Autism in China: Progress and challenges in addressing the needs of children and families. International Journal of School \& Educational Psychology, 7(2), 135-146. https://doi.org/10.1080/21683603.2019.1570885

Cui, F. (2016). A good example of parent advocacy for rights in inclusive education in China. Frontiers of Law in China, 11(2), 323-338. https://doi.org/10.3868/s050-005-016-0018-4

Delfabbro, P., Winefield, T., Trainor, S., Dollard, M., Anderson, S., Metzer, J., et al. (2006). Peer and teacher bullying/victimization of South Australian secondary school students: Prevalence and psychosocial profiles. British Journal of Educational Psychology, 76, 71-90. https://doi.org/10.1348/000709904X24645

Deng, M., Poon-Mcbrayer, K. F., \& Farnsworth, E. B. (2001). The development of special education in China: A sociocultural review. Remedial and Special Education, 22(5), 288-298. https:// doi.org/10.1177/\%2F074193250102200504

Due, P., Holstein, B. E., Lynch, J., Diderichsen, F., NicGabhein, S., Scheidt, P., et al. (2005). Bullying and symptoms among schoolaged children: International comparative cross sectional study in 28 countries. European Journal of Public Health, 15, 128-132. https://doi.org/10.1177/074193250102200504

Frankel, F., \& Whitham, C. (2011). Parent-assisted group treatment for friendship problems of children with autism spectrum disorders. Brain Research, 1380, 240-245. https://doi.org/10.1016/j. brainres.2010.09.047

Huang, A. X., Jia, M., \& Wheeler, J. J. (2013). Children with autism in the People's Republic of China: Diagnosis, legal issues, 
and educational services. Journal of Autism and Developmental Disorders, 43, 1991-2001. https://doi.org/10.1007/ s10803-012-1722-6

Huang, M., \& Zhou, Z. (2016). Perceived self-efficacy, cultural values, and coping styles among Chinese families of children with autism. International Journal of School \& Educational Psychology, 4(2), 61-70. https://doi.org/10.1080/21683603.2016.1130562

Kloosterman, P. H., Kelley, E. A., Craig, W. M., Parker, J. D., \& Javier, C. (2013). Types and experiences of bullying in adolescents with an autism spectrum disorder. Research in Autism Spectrum Disorders, 7(7), 824-832. https://doi.org/10.1016/j. rasd.2013.02.013

Li, X. (2016). A study of regular primary school teachers' attitude toward special students learning in regular classes. Journal of Suihua University, 36(4), 20-25. https://doi.org/10.3969/j.issn. 2095-0438.2016.04.005

Little, L. (2001). Peer victimization of children with Asperger spectrum disorders. Journal of the American Academy of Child and Adolescent Psychiatry, 40, 995-996. https://doi.org/10.1097/00004 583-200109000-00007

Liu, Y., Li, J., Zheng, Q., Zaroff, C. M., Hall, B. J., Li, X., \& Hao, Y. (2016). Knowledge, attitudes, and perceptions of autism spectrum disorder in a stratified sampling of preschool teachers in China. BMC Psychiatry, 16(1), 142. https://doi.org/10.1186/ s12888-016-0845-2

Maiano, C., Normand, C. L., Salvas, M. C., Moullec, G., \& Aimé, A. (2016). Prevalence of school bullying among youth with autism spectrum disorders: A systematic review and meta-analysis. Autism Research, 9(6), 601-615. https://doi.org/10.1002/aur.1568

Mccabe, H. (2003). The Beginnings of Inclusion in the People's Republic of China. Research and Practice for Persons with Severe Disabilities, 28(1), 16-22. https://doi.org/10.2511/rpsd.28.1.16

McCabe, H. (2007). Parent advocacy in the face of adversity: Autism and families in the People's Republic of China. Focus on Autism and Other Developmental Disabilities, 22(1), 39-50. https://doi. org/10.1177/10883576070220010501

National Academies of Sciences, Engineering, and Medicine (2016). Preventing bullying through science, policy, and practice. Washington, DC: The National Academies Press. https://doi.org/10. 17226/23482.

National People's Congress. (2018a). Law of the People's Republic of China on the protection of persons with disabilities. http:// www.npc.gov.cn/zgrdw/npc/xinwen/2018-11/05/content_20656 32.htm

National People's Congress. (2018b). Nine-year compulsory education law of the People's Republic of China. http://www.npc.gov.cn/ zgrdw/npc/xinwen/2019-01/07/content_2070254.htm

Noon, E. J. (2018). Interpretive phenomenological analysis: An appropriate methodology for educational research? Journal of Perspectives in Applied Academic Practice, 6(1), 75-83. https://doi.org/ 10.14297/jpaap.v6i1.304

Ochoa, T. A., Erden, E., Alhajeri, O., Hurley, E., Lee, K., Ogle, L., \& Wang, T. (2017). Disability laws and special education provisions in China, Kuwait, South Korea, Turkey, and the United States. International Journal of Special Education, 32(2), 325-354.

Poon-McBrayer, K. F., \& McBrayer, P. A. (2014). Plotting Confucian and disability rights paradigms on the advocacy-activism continuum: Experiences of Chinese parents of children with dyslexia in Hong Kong. Cambridge Journal of Education, 44(1), 93-111. https://doi.org/10.1080/0305764X.2013.860084

Olweus, D. (1993). Bully/victim problems among schoolchildren: Long-term consequences and an effective intervention program.
In S. Hodgins (Ed.), Mental disorder and crime (pp. 317-349). Sage Publications Inc.

Patton, M. Q. (2005). Qualitative research. Encyclopedia of Statistics in Behavioral Science. https://doi.org/10.1002/0470013192.bsa514

Reijntjes, A., Kamphuis, J. H., Prinzie, P., \& Telch, M. J. (2010). Peer victimization and accepting problems in children: A meta-analysis of longitudinal studies. Child Abuse \& Neglect, 34(4), 244-252. https://doi.org/10.1016/j.chiabu.2009.07.009

Rose, C. A., Espelage, D. L., \& Monda-Amaya, L. E. (2009). Bullying and victimization rates among students in general and special education: A comparative analysis. Educational Psychology, 29(7), 761-776. https://doi.org/10.1080/01443410903254864

Sohn, B. K., Thomas, S. P., Greenberg, K. H., \& Pollio, H. R. (2017). Hearing the voices of students and teachers: A phenomenological approach to educational research. Qualitative Research in Education, 6(2), 121. https://doi.org/10.17583/qre.2017.2374

Sterzing, P. R., Shattuck, P. T., Narendorf, S. C., Wagner, M., \& Cooper, B. P. (2012). Bullying involvement and autism spectrum disorders: Prevalence and correlates of bullying involvement among adolescents with an autism spectrum disorder. Archives of Pediatrics \& Adolescent Medicine, 166(11), 1058-1064. https:// doi.org/10.1001/archpediatrics.2012.790

Storch, E. A., Heidgerken, A. D., Geffken, G. R., Lewin, A. B., Ohleyer, V., Freddo, M., \& Silverstein, J. H. (2006). Bullying, regimen selfmanagement, and metabolic control in youth with type I diabetes. The Journal of Pediatrics, 148(6), 784-787. https://doi.org/10. 1016/j.jpeds.2006.01.007

Su, X., Guo, J., \& Wang, X. (2020). Different stakeholders' perspectives on inclusive education in China: Parents of children with ASD, parents of typically developing children, and classroom teachers. International Journal of Inclusive Education, 24(9), 948-963. https://doi.org/10.1080/13603116.2018.1502367

Sun, X., Allison, C., Auyeung, B., Matthews, F. E., Baron-Cohen, S., \& Brayne, C. (2013). Service provision for autism in mainland China: Preliminary mapping of service pathways. Social Science \& Medicine, 98, 87-94. https://doi.org/10.1016/j.socscimed.2013. 08.016

Twyman, K. A., Saylor, C. F., Saia, D., Macias, M. M., Taylor, L. A., \& Spratt, E. (2010). Bullying and ostracism experiences in children with special health care needs. Journal of Developmental \& Behavioral Pediatrics, 31(1), 1-8. https://doi.org/10.1097/DBP. 0b013e3181c828c8

Thornberg, R., \& Charmaz, K. (2014). Grounded theory and theoretical coding. The SAGE Handbook of Qualitative Data Analysis, 5, 153-169. https://doi.org/10.4135/9781446282243.n11

Van Cleave, J., \& Davis, M. M. (2006). Bullying and peer victimization among children with special health care needs. Pediatrics, 118(4), e1212-e1219. https://doi.org/10.1542/peds.2005-3034

Van Roekel, E., Scholte, R. H., \& Didden, R. (2010). Bullying among adolescents with autism spectrum disorders: Prevalence and perception. Journal of Autism and Developmental Disorders, 40(1), 63-73. https://doi.org/10.1007/s10803-009-0832-2

Xu, S. Q., Cooper, P., \& Sin, K. (2018). The 'Learning in regular classrooms' initiative for inclusive education in China. International Journal of Inclusive Education, 22(1), 54-73. https://doi.org/10. 1080/13603116.2017.1348547

Xu, Y., \& Zhu, M. (2016). "Pain" and "difficulty" of integrated education for children with ASD in China. Modern Special Education, 19. https://doi.org/10.3969/j.issn.1004-8014.2016.10.008

Zablotsky, B., Bradshaw, C. P., Anderson, C. M., \& Law, P. (2014). Risk factors for bullying among children with autism spectrum disorders. Autism, 18(4), 419-427. 
Zhang, D., \& Spencer, V. G. (2015). Addressing the needs of students with autism and other disabilities in China: Perspectives from the field. International Journal of Disability, Development, and Education, 62(2), 168-181. https://doi.org/10.1080/1034912X. 2014.998175

Publisher's Note Springer Nature remains neutral with regard to jurisdictional claims in published maps and institutional affiliations.

Hui Zhang is a current Ph.D. student of the University of California, Santa Barbara's Department of Education. Her research interests include parental support and advocacy in both school and community contexts and disability rights. Currently, she is researching parental advocacy in China and the reasons that have contributed to the development of the current disability rights paradigm in advocacy.
Chun Chen is a recent Ph.D. graduate of the University of California, Santa Barbara's Department of Counseling, Clinical, and School Psychology. Her research interests include juvenile risk and resilience, as well as the identification of social-emotional and social-ecological elements that promote favorable mental health outcomes and enable individuals to cope with negative experiences such as bullying victimization and problematic Internet use. 